\title{
Wear Behavior of Basalt Powder Reinforced Phenolic Resin Matrix Composites Brake Lining Pads
}

\author{
I.D.G Ary Subagia ${ }^{1,2, a^{*}}$, KT. adi Atmika ${ }^{1,2}$, Wayan Nata Setiadi ${ }^{1,2}$, \\ MD. Parwata ${ }^{1,2}$ \\ ${ }^{1}$ Mechanical Engineering, Faculty of Engineering, \\ University of Udayana (UNUD), Bukit Jimbaran - Badung Bali Indonesia 80361 \\ ${ }^{2}$ New Materials and Tribology Center (NMTC), Mechanical Engineering, \\ University of Udayana (UNUD), Bukit Jimbaran - Badung Bali Indonesia 80361 \\ aarsubmt@gmail.com
}

Keywords: Wear, Basalt powder, Composite, Brake lining pads.

\begin{abstract}
This paper explain the wear behaviour of composites phenolic resin with basalt powder reinforced on brake lining pads. Composite brake has been manufactured use compaction and sintering steps. The research aims to investigate wear characteristic of composite that tested using the Pin-on-disk according to standard ASTM G 99-95a. The weight fraction ratios are 30:70\%wt; 60:40\%wt, and 80:20\%wt were carried out. The basalt wear characteristic is compared between with and without treatment using the $5 \% \mathrm{NaOH}$. The experiment result reported that the rate of wear durability of the composite was $10.9 \%$ and $11: 38 \%$ of composite each composition. In conclusions, basalt has better environment characteristic than asbestos.
\end{abstract}

\section{Introduction}

Brake is one important component which is installed on all types of vehicle. Braking system is consisting of many parts like cylinder, disk rotor, master cylinder, pads and etc. Technically, the brake lining pads is an important part which mounted on a brake disk rotor for making friction with the wheel disc [1-3]. In other words, brake pads that installed on each brake set has function to absorb kinetic energy through friction between the disk and pad until vehicle stop. Lining brakes is composite material due to consist of the strengthening (i.e. fibers or powders) and polymers (thermoplastics or thermosetting) [4]. Presently, asbestos has widely applied and become the main material used as reinforcement of lining brake pads blended with other ingredients, which embedded in matrix of polymer. The positive characteristics of asbestos are water resistant, resistant on high temperature, and good friction. On the thermal characteristics, asbestos have higher thermal compared with silicates is stable up to $500^{\circ} \mathrm{C}$. Additionally, it is inexpensive price. Contrary, asbestos is dangerous for health and no environmental friendly. Here asbestos during friction produces much poisonous dust and it made cancer disease on humans because of asbestos dust tends to be mild, soft and easy to stick that would be making asbestosis and carcinogen. Consequently, international countries have been prohibiting use asbestos material. Besides that, all international standards like ECER 90, JASO, SAE also recommend have to use a non-asbestos material on lining brake pads.

Hereinafter, lining brake produced was generally developed through trial and error process, coupled with prior experience of manufactures, especially when government prohibits lining brake pad use asbestos [5]. Several Scientifics have carried out study for material that can substitute asbestos as lining brakes pads for all type of vehicles. Xin et al. [5] developed sisal fiber reinforced brake composites for study wear characteristic and friction. Their results, organic fiber is difficult to maintain in high temperature ranges of friction, even though its clean materials. Ikpambase et al. [6] have reduced contents of asbestos on lining brake pads of vehicle by using palm kernel fibers. Idris et al. [7] developed lining brake pads material using an organic material such banana peel. In addition, lining brake pad without metal material (i.e. copper, lead, tin, antimony trisulfide, and whisker materials) for developing an environmental friendly friction pads have studied by Yun et al. [8]. Other 
material for friction brake from hybrid composite reinforced with combination of potassium titanate whisker and aramid fibers have conducted by [9], and combination of ceramic and aramid fiber reinforced hybrid phenolic composites was developed by Patnaik et al. [10]. Moreover, Singh, et.al [11] designed brake pad hybrid phenolic composites based on the lapinus and aramid fibers reinforced. The result is enhancement of $\mu$-performance caused by increased lapinus contents with corresponding decrease in aramid fiber content. The wear characteristics and frictionless of newly design lining brake pad material was reported by [10, 12-15]. The optimization friction and wear for non asbestos lining brake pads also studied by Balaji, et.al [16]. In addition, Gultekin, et.al [17], reported the friction and wear characteristics influenced by applied loads on the sintered copper matrix composite brake pads against cast $\mathrm{Al}-\mathrm{Si} / \mathrm{SiCp}$ brake disc. Their results is the friction coefficient and wear characteristics was stable in all of applied load varieties generally depended on many factors i.e. the graphite content, applied normal load, and sliding distance.

In the context in order to develop newly material for lining brake pads, basalt as new member of organic material was introduced. Basalt is the sediment rock of volcano that contain chemically compound such as: magnesium, calcium, sodium, potassium, silicon and iron, along with traces of alumina $[18,19]$. Basalt has been widely applied on engineering products due to of their mechanical and physical characteristics few last ten years. Specifically, the strength and modulus of elasticity of basalt has a highest than glass, also it has better environment behavior compared with glass and asbestos. In particular, basalt has good advantages in mechanical properties and physical, thus widely applied on engineering products. Here basalt materials have properties more better than asbestos and environmental-friendly as reported by Kogan et al. [20].

The present study, in order to develop the brake lining pad that free of asbestos, the composite phenolic resin with basalt powder reinforced have been manufactured using the three kinds of weight fraction ratios. This research aims investigate the wear characteristic of composite that tested using the Pin-on-disk. This test is accordance standard ASTMD3171-09 for specimen production and ASTM G 99-95a for wear test.

\section{Experiment Procedure}

Basalt powder has been implemented as a strengthening of phenolic resin composites material of the vehicle brake linings. Basalt and Phenolic resin were used respectively produced by Reade International Corp and co. USA and Indopherin Jaya, Indonesia. The grain size of basalt is 0.074 millimeter. $\mathrm{NaOH}$ was employed for basalt powder treatment. A list of basalt material characteristics are presented as Table 1.

Table 1. Basalt characteristics.

\begin{tabular}{ll}
\hline Data fisik Basalt & Nilai (unit) \\
\hline Density & $2600-2630\left(\mathrm{~kg} / \mathrm{m}^{3}\right)$ \\
Tensile strength & $500 \mathrm{k}-550 \mathrm{k}(\mathrm{psi})$ \\
Temperatur sintering & $1050\left({ }^{\circ} \mathrm{C}\right)$ \\
Temperatur operasi & $-265-+700\left({ }^{\circ} \mathrm{C}\right)$ \\
Modulus of elastisitas & $9100-1100\left(\mathrm{~kg} / \mathrm{mm}^{3}\right)$ \\
Mohs Hardness @ $20^{\circ} \mathrm{C}$ & $5-9$ \\
Melting point & $1170\left({ }^{\circ} \mathrm{C}\right)$ \\
Heat resistance & $700-1000(\mathrm{deg} . \mathrm{C})$ \\
Elongation at break & $3.15(\%)$ \\
Modulus elastik & $89\left(\mathrm{~kg} / \mathrm{mm}^{3}\right)$ \\
\hline
\end{tabular}

In this work, three weight fraction composition ratio had been conducted such 30:70\%wt; 60:40\%wt and 80:20\%wt, which is produced accordance four phases i.e. blending, compaction, sintering, and cutting, respectively (see Fig. 1). Presently, mixture was pressured at loads 3 tons as long as 30 minutes under the room temperature. Then, the specimens are sintered at constant temperature of $200^{\circ} \mathrm{C}$ at least as long as $2 \mathrm{~h}$ for each ratio. Afterwards, specimens for each variant were cut according to standard ASTMD3171-09 with geometry as shown on Fig. 2a. Pin on disk test [21] 
was carried out accordance ASTM G 99-95a standard as exhibited on Fig. 2b. Table 2 shows the composition of every weight fraction ratio composite.

Table 2. The weight fraction composition of composite.

\begin{tabular}{ccccc}
\hline \multirow{2}{*}{ Composition } & \multicolumn{2}{c}{ Non Treatment } & \multicolumn{2}{c}{ Treatmen 5\% NaOH } \\
\cline { 2 - 5 } & $\begin{array}{c}\text { Basalt } \\
\text { powder }\end{array}$ & $\begin{array}{c}\text { Phenolic } \\
\text { Resin }\end{array}$ & Basalt powder & $\begin{array}{c}\text { Phenolic } \\
\text { resin }\end{array}$ \\
\hline I & 60 & 40 & 60 & 40 \\
II & 70 & 30 & 70 & 30 \\
III & 80 & 20 & 80 & 20 \\
\hline
\end{tabular}
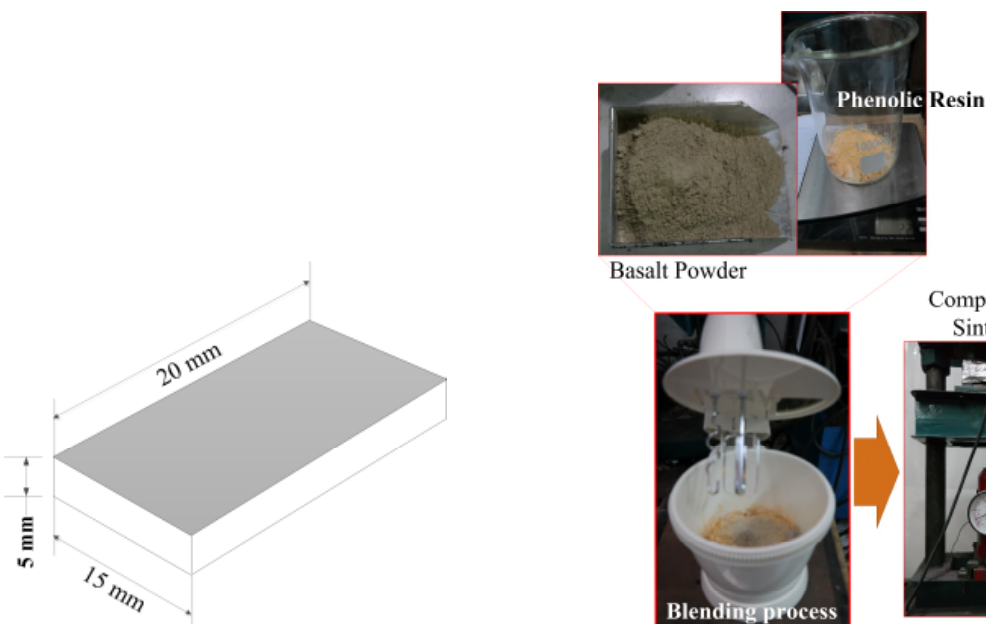

Fig. 1 a. Specimen geometry; b. Composite manufacture process.

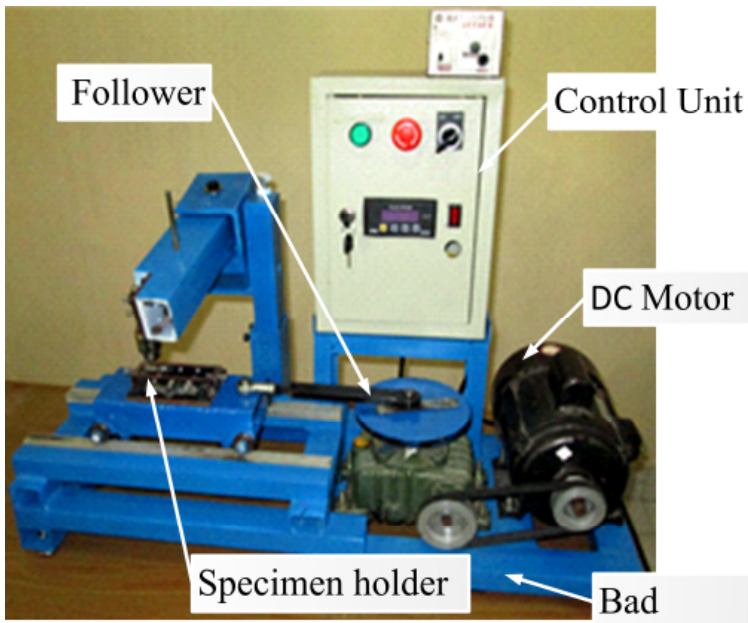

Fig. 2 Pin-on-disk Setup.

According to the traditional concept and following the composite rule was determined by as below:

$$
\begin{aligned}
& \omega_{c}=\omega_{m}+\omega_{f} \\
& W_{m}=\frac{\omega_{m}}{\omega_{c}}, W_{f}=\frac{\omega_{f}}{\omega_{c}} \\
& W_{m}+W_{f}=1
\end{aligned}
$$

In the formula $\omega_{c}$ is total weight of composite, $\omega_{f}$ is indicating total reinforcement weight, $\omega_{m}$ is weight of matrix, and $W_{f}$ is indicate weight fraction of reinforcement, $W_{m}$ is weight fraction of matrix. 
The wear measurement of composite phenolic resin matrix with basalt fiber reinforced can be reported following equation for conversion of mass lost to volume loss as below;

$$
V_{\text {loss }}=\frac{m_{\text {loss }}}{\text { density }} \times 1000
$$

then, the friction factor could be determined according to the Eq. 3

$$
\text { Wearing factor }=\frac{V_{\text {loss }}}{P . L}
$$

In this test, semi-spherical surface friction was conducted, so the surface wearing of composites is calculated following equation;

$$
P=a . l \rightarrow l=\frac{\pi r \varphi}{180^{\circ}}
$$

then, the mass loss per cross-section area of composite determined following the equation below:

$$
z=\frac{m}{P}\left(\frac{g}{\mathrm{~cm}^{2}}\right)
$$

The average results of wear resistance calculation basalt reinforced phenolic resin composite are shown in Fig. 4.

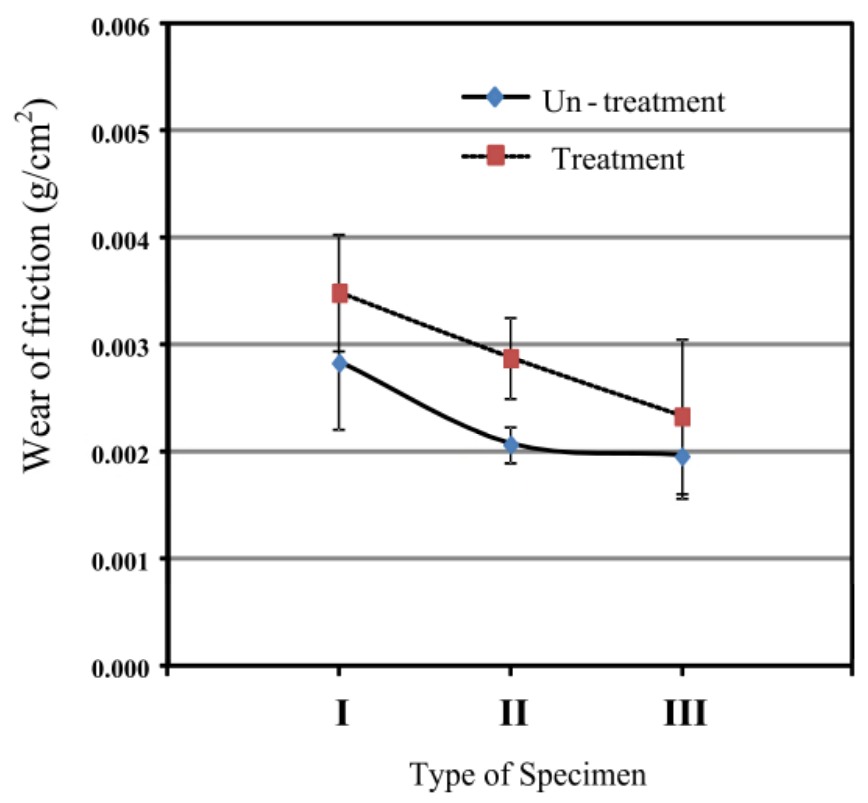

Fig. 4 Wear friction of the composite.

\section{Test Results}

Fig. 4 shows the wear friction diagram of brake lining pads using composite phenolic resin with basalt powder reinforced. It was seen for comparison between the treated and without treated of basalt powder was examined. The composite with treatment by $5 \% \mathrm{NaOH}$ has increased the toughness of wear friction for all variation weight fractions. However, increasing of basalt powder values had decreased significantly the wear friction of composite. Particularly, the highest wear friction toughness was shown by composite with weight fraction ratio $60 \%$ wt basalt; $40 \%$ wt penolic resin, and the lowest value is shown by weight fraction ratio $80 \%$ wt:20\%wt. The decreasing wear friction toughness is caused by decreasing bounded of matrix to the powder. Here, powder diameter also influences the toughness of wear friction. According to the result the conclusion is the composition of 
the number of grains and the amount of matrix has a significant influence on the rate of wear caused by friction of basalt epoxy composite material. Besides, basalt is a natural alternative material that can be used as an alternative material for asbestos brake pad replacement.

\section{Conclusion}

This study concludes that the wear friction toughness of basalt powder reinforced phenolic resin composite was increase significantly. The increasing of wear friction toughness effect of 5\% treatment by $\mathrm{NaOH}$ is $18.75 \%$. Additionally, powder diameter significantly influences the wear friction of composite. Besides that, basalt is good natural material that can used to substitute of asbestos because basalt has environmentally friendly

\section{Acknowledgement}

The author wishes to thank the Ministry of research, technology and higher education over research funding that has been given. Thanks also to Mechanical engineering (UNUD) for the provision of laboratory facilities.

\section{References}

[1] K. W. Liew and Umar Nirmal, Frictional performance evaluation of newly designed brake pad materials, Mater. Des. 48 (2013) 25-33.

[2] S. N. Nagesh, C. Siddaraju, S. V. Prakash and M. R. Ramesh, Characterization of Brake Pads by Variation in Composition of Friction Materials, Proc. Mater. Sci. 5 (2014) 295-302.

[3] D. S. Yawas, S. Y. Aku and S. G. Amaren, Morphology and properties of periwinkle shell asbestos-free brake pad, J. King Saud Univ. - Eng. Sci. 28 (2013) 103-109.

[4] W. Österle, C. Deutsch, T. Gradt, G. Orts-Gil, T. Schneider and A. I. Dmitriev, Tribological screening tests for the selection of raw materials for automotive brake pad formulations, Tribol. Inter. 73 (2014) 148-155.

[5] X. Xin, C. G. Xu and L. F. Qing, Friction properties of sisal fibre reinforced resin brake composites, Wear, 262(5-6) (2007) 736-741.

[6] K. K. Ikpambese, D. T. Gundu and L. T. Tuleun, Evaluation of palm kernel fibers (PKFs) for production of asbestos-free automotive brake pads, J. King Saud Univ. - Eng. Sci. 28 (2016) 110-118.

[7] U. D. Idris, V. S. Aigbodion, I. J. Abubakar, C. I. Nwoye, Eco-friendly asbestos free brake-pad: Using banana peels, J. King Saud Univ. - Eng. Sci. 27 (2015) 185-192.

[8] R. Yun, P. Filip and Y. Lu, Performance and evaluation of eco-friendly brake friction materials, Tribol. Inter. 43 (2010) 2010-2019.

[9] M. Kumar, B. K. Satapathy, A. Patnaik, D. K. Kolluri and B. S. Tomar, Hybrid composite friction materials reinforced with combination of potassium titanate whiskers and aramid fibre: Assessment of fade and recovery performance, Tribol. Inter. 44 (2011) 359-367.

[10]A. Patnaik, M. Kumar, B. K. Satapathy and B. S. Tomar, Performance sensitivity of hybrid phenolic composites in friction braking: Effect of ceramic and aramid fibre combination, Wear, 269 (2010) 891-899.

[11] T. Singh and A. Patnaik, Performance assessment of lapinus-aramid based brake pad hybrid phenolic composites in friction braking, Archives Civil Mech. Eng. 15 (2015) 151-161.

[12] K. W. Liew and U. Nirmal, Frictional performance evaluation of newly designed brake pad materials, Mater. Des. 48 (2013) 25-33. 
[13] B. K. Satapathy and J. Bijwe, Composite friction materials based on organic fibres: Sensitivity of friction and wear to operating variables, Comp. Part A: Appl. Sci. Manuf. 37 (2006) 1557-1567.

[14] P. C. Verma, Luca Menapace, Andrea Bonfanti, Rodica Ciudin, Stefano Gialanella and Giovanni Straffelini, Braking pad-disc system: Wear mechanisms and formation of wear fragments, Wear, 322-323 (2015) 251-258.

[15]P. V. Gurunath and J. Bijwe, Friction and wear studies on brake-pad materials based on newly developed resin, Wear, 263 (2007) 1212-1219.

[16] S. Balaji and K. Kalaichelvan, Optimization of a Non Asbestos Semi Metallic Disc Brake Pad Formulation with Respect to Friction and Wear, Proc. Eng. 38 (2012) 1650-1657.

[17] D. Gultekin, M. Uysal, S. Aslan, M. Alaf, M. O. Guler and H. Akbulut, The effects of applied load on the coefficient of friction in Cu-MMC brake pad/Al-SiCp MMC brake disc system, Wear, 270 (2010) 73-82.

[18] V. Dhand, G. Mittal, K. Y. Rhee, S. J. Park and D. Hui, A short review on basalt fiber reinforced polymer composites, Comp. Part B: Eng. 73 (2015) 166-180.

[19] V. Fiore, T. Scalici, G. Di Bella and A. Valenza, A review on basalt fibre and its composites, Comp. Part B: Eng. 74 (2015) 74-94.

[20]F. Kogan and O. Nikitina, Solubility of chrysotile asbestos and basalt fibers in relation to their fibrogenic and carcinogenic action, Environ. Health Perspect. 102 (1994) 205-206.

[21] J. Wahlström, D. Gventsadze, L. Olander, E. Kutelia, L. Gventsadze and O. Tsurtsumia, et al. A pin-on-disc investigation of novel nanoporous composite-based and conventional brake pad materials focussing on airborne wear particles, Tribol. Inter. 44 (2011) 1838-1843. 